\title{
Stakeholder identification and salience in purchasing: An empirical study from UK hospitals
}

\author{
Pearce Madhlambudzi ${ }^{1}$ and Christos I. Papanagnou ${ }^{1}$
}

Salford Business School ${ }^{1}$, Maxwell Building, University of Salford, The Crescent, Salford, Manchester, M5 4WT, United Kingdom. email: c.papanagnou@salford.ac.uk

\begin{abstract}
The lack of systematic processes for stakeholder identification and the omission of key stakeholders in UK hospitals cause significant delays in purchasing processes. This is reinforced by the strict tender processes that follow in making their purchases as a matter of assurance of fairness and competition. This paper presents a descriptive analysis of decision-making processes when the public hospitals purchase diagnostic equipment, and it discovers how the hospitals use stakeholder identification and salience during the purchase of diagnostic equipment. With the aid of purposeful case studies and semi-structured interviews, we explore how stakeholder salience is concentrated on the administrative personnel who had the role to implement organisational policy, and technical experts who make sure that the right equipment was bought. Last, this study provides an insight into how stakeholder groups share the premises of the public hospitals' decision-making process by considering the attributes of power, urgency, legitimacy, and proximity.

Keywords - Purchasing, Procurement, Stakeholder identification, stakeholder salience, United Kingdom, Healthcare economics and management, NHS Trust, Hospital management, decisionmaking, diagnostic equipment, semi-structured interviews.
\end{abstract}




\section{Introduction}

World's economic stagnation has brought a health crisis. Funding gaps are emerging due to increased demand (it appears that more people are living longer with more complex diseases), need to meet expectations of patients as well as introduce new technology even under austerity. Operational costs are growing while Capital investments have dried up. In the National Health Service (NHS) organisation, purchasing has been identified as one area whose immediate reform can quickly bring benefits (Newhouse, 1992; Smith and Flanegin, 2004; Congressional Budget Office, 2007). Alone, this is bound to fail unless new, innovative approaches to managing resources and novel supply chain practices are adopted.

Current and future challenges for NHS could be attributed partly to the previous success of its healthcare initiatives as it can be shown in Figure 1. Average life expectancy is augmenting and this affects health services. This means people now live longer, but as good it may sound, this will bring with it increased conditions and illness such as dementia, a condition very rare a long time ago. Furthermore, there has been a change in the burden of disease, 15 million people in the population present with a long-term condition such diabetes, depression and high blood pressure, taking up 50\% of all GP appointments. In hospitals, they take up 70\% of days in a Hospital bed and $70 \%$ of total Health spend in England alone. NHS has since inception been receiving a meagre $4.8 \%$ of National income. This way of operating in the health sector is unsustainable for the vast majority of countries. For instance, publicly funded health sector's budget deficit in the United Kingdom is expected to hit the sky, an estimated £30bn deficit by the year 2022. This gigantic problem calls for new and innovative ways of managing. There is now a need for an active form of management, one that focuses on relationships, since most of the business tasks are associated with relationship management.

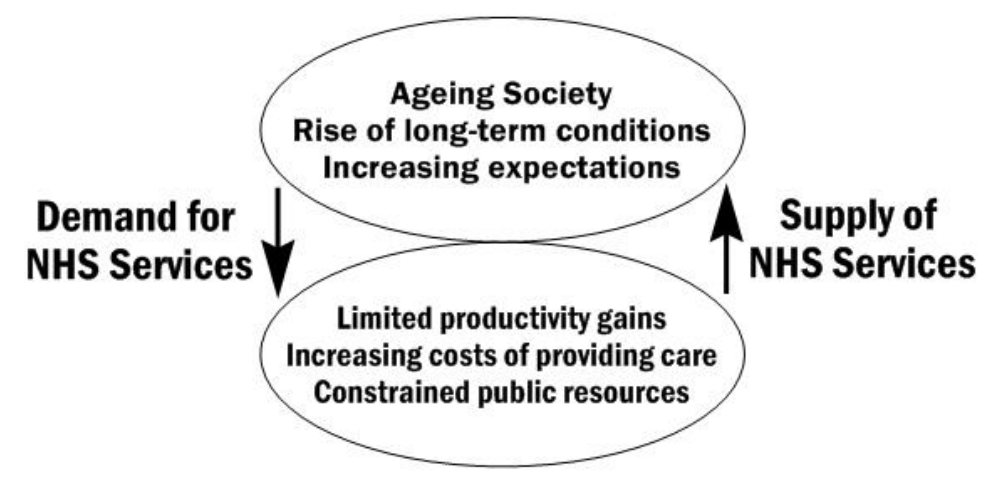

Figure 1. Current and future pressure on Health Service

Current stakeholder models, despite they are used as tools for analysing stakeholder issues, they are lacking when it comes to the provision of specific proposals that would explain stakeholder dynamics during the project lifecycle. In theory, it is possible to analyse secondary stakeholder behaviour during the different phases of the project lifecycle and explain their influence on project management's decision making by using a number of factors and perspectives. The proposed analytical framework, which is relatively recent to stakeholder literature, adopts a lifecycle perspective on stakeholder behaviour. Factors such as project uniqueness and its irreversibility of decision making, impact stakeholder salience and irreversibility of the decision-making process as well as the capacity of stakeholders to act and use different strategies. For this study "salience" is determined to how stakeholders' requests are prioritised in a decision-making process.

The way an institution may respond to resistance by a secondary stakeholder is governed by institutionalised practices as well as standards of the pertaining industry. Usually, these effects 
manifest in early phases of a project and could be due to the fact that the implementing organisation decides to move as fast as possible, thus turns a blind eye to local resistance (Aaltonen and Kujala, 2010). Hence, it is important the management understand secondary stakeholders' attributes, concerns, and behaviours in projects. This may assist the level of engagement of secondary stakeholders in project management's decision-making process. In order to bridge this gap, this paper suggests a qualitative approach based on semi-structured interviews using a project lifecycle approach.

The focal process constitutes a project from a healthcare setting. This is based on two NHS projects and a private healthcare provider who had decided to replace their equipment. The preparation of this project began by placing a project team together. The brief was to produce specification culminating in the production of a project proposal. However, it is the contention of this study that some key stakeholders - who were engaged in the past in successful proposals - were not consulted earlier in the whole process or even throughout. To understand how hospital management use stakeholder identification and salience during purchasing of diagnostic equipment, the following questions are examined:

1. How are stakeholders identified?

(a) What is the stakeholder identification in each case?

(b) What are the similarities or differences across cases?

2. What was the stakeholder salience?

(a) What stakeholder's attributes were most salient for each case?

(b) What are the similarities or differences across cases?

\section{Literature Review}

\subsection{The purchasing function for equipment in healthcare}

Purchasing as a role has recently risen to prominence in many organisations who strive to improve their balance sheets. In this period of austerity, sectors like healthcare are increasingly taking advantage of this given their dwindling budgets as well as foreseen threats of increasing purchasing costs in the coming years (Johnson, 2013). Freeman and Cavinato (1990) proposed that those companies wish to get added value, they need to link their purchasing processes with organisational strategies. The equipment sourcing process is composed mainly of the following steps:

- Service specification

- Supplier selection

- Contact agreement consists of ordering, exploiting the service or using equipment, and finally evaluation of service or equipment (Gelderman and Van Weele, 2005).

A purchasing process should satisfy all business needs and their requirements. However, the purchasing of capital goods with a service component differs from the general purchasing process of goods (Fitzsimmons et.al., 1998). The service component can be defined as, "a process consisting of a series of more or less tangible activities that usually it takes place in the interaction between the organisation and the supplier", (Granroos, 2000). Often, great efforts are made when it comes to differentiating goods from services. In fact, sometimes goods are always followed by a service component (Boudewijn et al., 2010). In the case of diagnostic equipment, this can be supplied by the manufacturer with a service arrangement that covers installation, commissioning, training, maintenance, software and spare parts. 
In order for purchasing processes to run smoothly, there is always a need to align business units with purchasing objectives and strategies (Cavinato, 1999). This helps organisations to capture attention across all business units. Thus, to ensure proper business alignment the sourcing team has to be crossfunctional. The users should lead the whole process whereas sourcing team provides a facilitative role, which starts as early as before the pre-contract phase. Next, in specification phase, stakeholders are identified as a group of interest leading to perfect suppliers' selection even in early stages (Axelsson and Wynstra, 2002; van der Valk and Rozemeijer, 2009).

In life cycle management of diagnostic equipment, contracts are based mainly on operation and maintenance whereas suppliers receive payments only after carrying out work or services of an agreed number of hours. However, outcome measures are gaining in popularity as a basis of a contract (Morse et al., 2008). In this category, payment is based on performance. The motive for this migration is that they are expensive and less restrictive, thus, more freedom is given for innovativeness and creativity of supplier (Martin et al., 2002). In a loosely governed relationship, there is potential for opportunistic behaviour by either party or both. The solution is usually in the form of active management. According to Cousins et al. (2011), in order to measure suppliers, the basis must be on business goals and strategies. The best way to achieve this is by entering into a collaborative working relationship with a supplier. Hence, it is important to use collaborative KPIs that can measure both supplier and buyer influence (Akkermans and van Oppen, 2006). The purpose of evaluation in a purchasing environment has the following results: provides a feedback for performance, supports better decision making, and promotes better communication between buyer and seller. Evaluation measures can be price performance, innovation, supplier performance and strategic performance.

\subsection{Stakeholder Identification and Salience}

To better understand and analyse partnership relationships, a stakeholder identification and salience framework was developed for this study. Stakeholder identification and salience are two concepts developed to assess the critical interrelationships and linkages between stakeholders. Both concepts are derived from stakeholder theory. Often used for its business applications, stakeholder theory is a way in which business can improve their relationships with stakeholders by understanding their value, which guides their interactions toward future success. In this section, stakeholder theory will be outlined and then the stakeholder identification and salience framework and its applications will be discussed.

Mitchell et al., (1997) by performing a literature review of stakeholder identification and salience ferreted out that there is a vague stakeholder definition. They came up that relatedness, malleability, and issue based factors impact individual perception. Thus, identifications are unique and require a detailed analysis of attributes that give a clear determination. Various ways of identifying stakeholders exist. Carroll (1993) sought to identify stakeholder groups by their primary or secondary standing. Goodpaster (1991) focussed on defining stakeholders by their fiduciary or lack of it. Friedman and Miles (2002) focussed on compatibility or incompatibility with each other. Managers when considering claims of competing stakeholders, often find themselves being favourable to the merits of one claim over the other. This behaviour is defined as Salience (see Kamal et al., 2015; Neville et al., 2004). Stakeholder attributes come in four types. These are power, legitimacy, urgency, and proximity. All together they contribute to what is known as stakeholder salience (Nguyen et al., 2009). 


\subsubsection{Stakeholder Power}

Frooman (1999) proposed various categories of power. However, scholars tend to use only two perspectives of power, i.e. the resource occupation and the relationship dependency. Cavanaugh (1984) looks at power from an individual angle under the resource occupation category. The outcome of this is that like in resource-based theory he proposes that the more resources needed by organisations, the higher the power they possess. Resource, in this case, is a term used very loosely and it can take any form. This view of power can be traced all the way back to Etzioni (1964) who brought forth three different types: coercive power, utilitarian, and social power, as explained below:

Coercive-power exercised through the use of physical resources such as violence or threatening with weapons. Utilitarian-power exercised through the influence of material possession such as money, personal goods, and services. Social-power exercised through the use of symbolic resources such as prestige, esteem, and acceptance. On the other hand, Freedman and Reed's view of power are more on the view of corridors of power (e.g., at boardroom level). Their view although considered formal it encompasses aspects like voting power, economic power, and political power. Voting-power is formal in nature and is often bestowed from organisational authority or hierarchy as seen in shareholder funds or minority interests. Economic-power within a marketplace such as due to market share/size commanded. Political-this is power usual derived from playing the political process to one's advantage.

\subsubsection{Legitimacy}

Stakeholder legitimacy is a very old attribute. Phillips (2003) traced the origins as far back as just after Freeman's (1984) pioneering the notion of stakeholder theory. The task of classifying stakeholder claims can be achieved by considering the legitimacy of their claims. The perception when viewing actions of stakeholders, when their actions are either desirable or not, is called stakeholder legitimacy. However, this is a view that has been moulded within a system of norms, values, beliefs and definitions.

Donaldson and Preston (1995) went further by separating stakeholder and influence. They highlighted the fact that some people can impact events without being stakeholders (e.g., media and competitors), nevertheless, they cannot be considered themselves stakeholders, as the organisational goals are not created for the purpose of fostering their well-being. Thus, they can only be used to reduce the sphere of influence of a stakeholder or to help identify one. Not everyone is in agreement with this narrow view, particularly, scholars from a strategic management point of view. Mitchell et al., (1997) claim that powerful constituencies are stakeholders while Frooman (1999) brings up the fact that certain entities may be characterised as stakeholders if they can affect the direction of the organisation and/or project. Hence, managers should consider claims based on their potential to impact a project activity or strategy.

\subsubsection{Urgency}

Sometimes a stakeholder claim can be based on the form of Urgency. Mitchell et al.. (1997) consider this to be in terms of time sensitivities or its importance to the stakeholder. Therefore, time-related factors such as the threat of resources' unavailability, rates of return, political agendas, administrative calendars and project schedule can impact urgent levels. Urgency can either be appraised from a perspective of the short-term economic results and long-term sustainability (Driscoll \& Starik, 2004).The short-term view would cover such issues as cost-benefit analysis, rates of return and changes in stock prices. On the other hand, long-term sustainability considers such views as environmental catastrophes (e.g., urban sprawl, coastal developments, biodiversity loss and 
endangerment of species extinction). There is no consensus, however, as to which factor is more effective on stakeholder salience. Parent and Deephouse (2007) raised the following questions, which are still a lively debate over the diagnostic services: Where stakeholder characteristics have the most important effect on formulating decision-making strategies? Is the result consistent across different hierarchical levels and project types?

\subsubsection{Proximity}

The attribute of proximity is as important as that of urgency because both involve the aspect of time (Driscoll \& Starik, 2004). Proximity can indicate that state, quality or fact of being near or next in space, time or order. Proximity according to this study can be categorised into four aspects:

1. That associated with physical sharing. This can be due to the fact that organisations share same or neighbouring physical space.

2. That of sharing interests. Here organisations are in proximity if they share same or similar ideas, approaches, and actions (e.g., suppliers on the value chain).

3. That associated with omnipresent of an organisation. Thus, the organisation is virtually everywhere.

4. That associated with the likelihood of an organisation to form partnerships with a preferred group of stakeholders due to reasons of being complimentary of missions, strategies, structures, resources or members.

This paper attempts to cover the literature gap by focussing on diversified decision-making processes when hospitals purchase diagnostic equipment. Thus, it helps top management to make wise decisions in various projects that have temporarily limited endeavours and they are characterised by different lifecycle phases. It generates also a unique context for the study of stakeholder behaviour. Every lifecycle phase has some characteristics of its own, distinct from those of the next project (Rauner and Heidenberger, 2002). These characteristics tend to affect the level stakeholders take action, the way they set up strategies and the project management's preference while they are taking into consideration each and every stakeholder's claims. Further, this paper aims to increase the understanding of the fluctuations associated with stakeholder behaviour in different phases of the project lifecycle.

Our study is based on research performed on purchasing diagnostic equipment projects within the business unit of pathology at two NHS hospitals. Since the emphasis of this paper is on stakeholder identification and purchasing processes for diagnostic equipment we opt for an approach, which summarises all our key findings, rather than presents and discusses any similarities or differences between the two NHS hospitals. As a result, this work intends to provide useful ideas and suggestions for improving the actual purchasing process of diagnostic equipment and define factors for stakeholder accountability. Our findings were derived from semi-structured interviews conducted among the people who were involved in making decisions like when/whom/what/where to outsource laboratory diagnostic equipment. Overall, 121 delegates were interviewed, which captures $79 \%$ of potential interviewees across two organisations. This type of analysis focuses on the content of narratives. In order to understand stakeholders taking action, and apply various stakeholder influence strategies during a project life cycle, our research design is used to analyse a tender project carried out at a Health Institution (Eisenhardt, 1989). Also in order to bring in a checking mechanism, several document analyses (Guidelines for Hospital Procurement) were also undertaken. This was meant to ensure validity. 
Last, this study considers the following phases of a purchasing process: Specification, supplier selection, and contractual phase. The decisions made at one phase feed into the other. If stakeholders miss participation in one of these phases, they might lose influence as resolutions at each phase tend to be irreversible. Thus, we investigate how power, legitimacy, urgency, and proximity were considered in decision-making processes at each stage.

\section{Cases}

\subsection{West Cumberland Infirmary}

West Cumberland Infirmary is run by North Cumbria University Hospitals NHS Trust which is part of Northumbria Healthcare NHS Foundation Trust. It is a secondary care provider of acute hospital services in north Cumbria and their services are based at the Cumberland Infirmary in Carlisle and the West Cumberland Hospital in Whitehaven. User consultation is recognised as an important aspect of procurement to ensure that goods and services meet the needs of patients and staff. The purchasing department supports the Trust Procurement Group as a method of consultation on commonly used medical consumables and devices. It also liaises directly with clinicians and department heads on individual purchases as well as supporting consortium evaluation meetings within the trust.

\subsection{Northampton Healthcare NHS Trust}

Northamptonshire Healthcare NHS Foundation Trust (NHFT) offers many of the NHS services that are provided outside the hospital and in the community such as physical, mental health and speciality services. They have sites across the country including in Corby, Daventry, Kettering, Northampton and East Northants.

\section{Results and Implications}

The stakeholder and salience analysis was meant to identify the stakeholders in the purchase of diagnostic equipment in a hospital and how they interact during various stages of the process. The study also takes into account instances whereby key stakeholders may be left out of the process, reasons for their exclusion and implications to the entire process. This research found that different stakeholders participated in the procurement process at each stage and the importance of their contribution varied. The stakeholder's role is also analysed in terms of how the attributes of power, urgency, legitimacy and proximity were reflected in the selection of stakeholders who participated in the procurement process. The following stakeholders were identified by the participants.

\subsection{Chief Financial Officer (CFO)}

All participants identified the CFO as a key stakeholder in the process as they ultimately have to approve payment for the new equipment. The role of CFO is to ascertain the availability of resources so that the procurement team makes informed plans. Power: While the CFO does not participate in the specification of equipment and supplier selection, his/her input is very important as he/she will be in a position to stop the implementation of a process that disregards his/her guidelines. This finding is in line with Kanter (1983), who defines stakeholder power the skill for someone to get things moving in a desirable manner.Urgency: CFO's role is found as being very important to the procurement process as he/she acts as the observer and guardian of financial resources. Legitimacy: The CFO is very important 
to the procurement process since the latter cannot be processed without financial resources. If CFO fails to cooperate in the procurement process that would cause problems since he/she will not be able to directly affect decisions made by the procurement team. According to Phillips (2003) managers are considered to know who are stakeholders, on what basis they merit such status, and how they relate to the focal organisation. Proximity: Apart from his/her role in its acquisition the CFO has no central role in utilisation. While the equipment in most cases is brought under managed services contracts, goals have been made in line with honouring the service contract and managing the cost savings which come as a result of the new equipment.

\subsection{Laboratory Department (LD)}

LD consists of main users of diagnostic equipment and it is central to hospital's operation. They are the ones to use it they have a key interest in determining specifications that are convenient to them. In $50 \%$ of the cases, it is found that the laboratory personnel was determined to stick with the same supplier in order to make it easier to transfer information from the old equipment to the new one. As a result, they have a key role in both specification and supplier selection. In some of the cases, they played a pivotal role in identifying the need for new equipment as this was based on an increased workload and unreliable performance of their aged machines.

Power: Despite being the core users of the equipment laboratory staff was aware that administrators would not approve the project if their guidelines were not followed. They had to provide as much detail as possible in their specifications in order to convince them that the equipment they opted for was clearly justified, which is often a common practice in public organisations (Winstanley et al., 1995). Urgency: LD considered that the replacement of the diagnostic equipment was critical considering the increased workload, ageing of the old equipment and the need to access new technologies which are offered by the latest models. The laboratory's representation in the procurement process is also critical since they are the main users of the equipment (Mitchell et al., 1997). Legitimacy: LD cannot be left out of a successful procurement process since they are the main users of the equipment and a process that excludes them could possibly end up with an unsuitable purchase. Laboratory personnel are aware of some very important specifications that can be looked for in an analysis when purchasing such as specificity, precision, accuracy etc. The department is also the accountable body to CPA (Clinical Pathology Accreditation) and CQC (Care quality commission), so through their guidelines, they make sure equipment conforms to set standards. Without their expertise, administrators would be tempted to buy the item which has the least cost but which may not meet the hospital's needs adequately (Rowley, 1997). Proximity: LD is very central to the utilisation of the diagnostic equipment that was purchased. Their goal is to reduce the waiting time for test results and also cut the costs as a result of having the new equipment. By participating in the procurement process, the department has benefitted because they possess the most suitable equipment.

\subsection{Procurement Committee (PC)}

Once all processes are carried out, PC is ultimately responsible for going through with the agreed transaction. Their involvement in identifying the need for new equipment is not significant but they have the liability to ensure that both the rules on items specifications and supplier engagement are met. While technical departments were keen to simply upgrade their existing equipment, people within PC insisted that tender procedures should be followed in identifying suppliers. In each case, they led the formation of a PC to oversee the steps required in identifying a supplier and making the eventual purchase.

Power: Throughout our study, PC made it clear that unless tender procedures were followed, no purchase would be made. Therefore, all the other stakeholders had to abide by this otherwise the whole 
project would have failed (Spekman et al., 1997). The technical team had to be very systematic in their specifications in order to convince the PC that their decisions were above board. As an outcome, stakeholder power within PC goes beyond the positional, resource and expert sources as defined by (Nguyen et al., 2009). Urgency: The role of the procurement team is to ensure fairness and transparency in the selection of the supplier, and once this is done to get the best terms for undertaking the transaction. Thus, PC role is ensuring that financial resources are used to the best advantage of the hospital ensuring long-term sustainability (Driscoll \& Starik, 2004). Legitimacy: The procurement team is vital to the purchasing process in hospitals as no business can be conducted without their involvement. If they fail to cooperate, no progress would be made much to the detriment of the hospital. PC is also empowered to affect the decision by nullifying the selection process at some stage or disqualifying some bids in cases when tender procedures have been flouted. This type of legitimacy is described by Philips (2003) as derivative since claims raised by PC are adjudicated based on the likelihood to impact NHS. Proximity: When the purchase is made, PC maintains a central role in ensuring the availability of related consumables and facilitating repairs, maintenance and procurement of spares. On the basis of technical information, specific goals around the maintenance cycle and consumption of consumables for the new machinery are settled. Finally, yet importantly, PC superintend purchasing process by enlightening other members on the procedures ensuring faster progress and less conflict in future procurement activities involving the same team members. This is very important as according to (Finch et al., 2015) the experience of PC stakeholders determines the extent to which they have in the focal organisation (NHS Trust).

\subsection{Accounts Department (AD)}

In cases when equipment is supposed to be replaced either because of the lease-end or when a book value is below acceptable thresholds, $\mathrm{AD}$ is in charge of identifying this (otherwise, it is completely left out of the process). However, our study revealed that their role appeared merely to inform relevant stakeholders of this fact and step back while the replacement process is handled by other stakeholders.

Power: AD plays an advisory role in raising an alert when equipment needs replacement, and, therefore, it is rather a product of social relationships Dahl (1957). Urgency: AD liability is terminated once the need to acquire new equipment has been agreed on. However, they do trigger the entire process in cases. Thus, AD may speed up the stakeholder claims in case there is a call for immediate attention (Aaltonen and Kujala, 2010). Legitimacy: AD confirms that new equipment is due in terms of the hospital's accounting standards and, consequently it prevents time to waste in debating whether the purchase is necessary. AD operates as normative stakeholders who always tend to ensure that any equipment acquisition would be beneficent for the NHS (Philips, 2003). This is extremely important because it facilitates better PC efforts in convincing other stakeholders about the need. If there is no cooperation between these two departments, this could result in the acquisition being delayed as the PC might deem it necessary to make the purchase at a later date. Proximity: AD has no direct role with the new equipment apart from recording the new asset and tracking its book values over the years. By participating in the process $\mathrm{AD}$ has a deeper understanding of its role in tracking asset values so as to inform the organisation timeously about assets that need replacement (Frooman, 1999).

\subsection{Biomedical Department $(B D)$}

BD was identified by interviewees as a key stakeholder but in practice, they are left out of the procurement process entirely, and, subsequently, it has lost the attribute of power in the process. Urgency: By excluding BD from procurement process, PC faced the risk of being misled by suppliers and purchase equipment that was inappropriate for the hospital's needs. The need to rectify such a situation would inevitably lead to delays in commissioning, which according to (Cavinato, 1999) resulting in higher costs. Legitimacy: In the hospital, biomedical engineers may provide advice on the 
selection and use of medical equipment, as well as supervise its performance testing and maintenance. It is, therefore, odd that they are being left out in the process of purchasing diagnostic equipment. Their participation is very important to attest that the most suitable equipment is bought. Proximity: Once it has been acquired, biomedical engineers have the duty to advise laboratory personnel that they make the best use of the equipment to ensure optimum outputs and machinery longevity. If they had participated in the process they would have been in a position to draw a plan for the management of the equipment and influence strategies (Frooman, 1999).

\subsection{Estates Department (ED)}

ED was also left out in the procurement process. This resulted in delays in installing the equipment since in some cases it was found that after delivery, water points and electrical supplies had to be adjusted to enable its installation. Urgency: The procurement process ignored urgency in dealing with ED resulting in waiting time after the diagnostic equipment was received. Involving ED at specification stage would have ensured that the new equipment was commissioned sooner, providing transparency and great levels of flexibility (Donaldson and Preston, 1995). Legitimacy: By considering the fact that they are responsible for preparing facilities - that are used for operating the equipment ED should have been actively involved so that they could do the necessary groundwork before delivery. Proximity: The role of ED is very crucial to the utilisation of the equipment but this was overlooked by PC. If they had been engaged they would have developed goals that would ensure that preparations for housing the new equipment were completed before its arrival.

\subsection{Primary care users (PCU)}

PCU, represented by General Practitioners (GPs) were also left out completely of the procurement process. The reason for excluding them (and consequently eliminating their power) was based on the view that they lacked technical knowledge and therefore could not contribute. Urgency: This attribute was believed to be absent since they were considered to be unimportant to the entire process. Legitimacy: On numerous occasions, some tests are still being outsourced, resulting in long results release windows. Consultation with PCU might have been necessary since in some cases they may be prepared to pay more for results that come out earlier. Proximity: Fifty percent of the capacity of the hospital's diagnostic equipment is by GPs, making them very central to its utilisation. The equipment is also very central to the GPs' operations and it makes sense that when formulating their goals, the availability of the diagnostic equipment plays a major part. Thus, PCU should be engaged with purchasing process since the utilisation of the diagnostic equipment by them helps to assess the quality and provide feedback on how alternative options may be considered in the future (Nguyen et al., 2009).

\section{The Process of Purchasing Diagnostic Equipment in the Health Sector}

\subsection{Identification of need}

The process starts off with the identification of the need to purchase new equipment. Three cases emerged in which there was a need to purchase new equipment. Case One: AD realised that the book value of the existing equipment had reached the end of its lifespan as determined by the book value. After doing this they thereby notified the users that they need to source for a replacement. In this scenario, there is no debate as to whether the acquisition should go ahead. Case Two: The laboratory realised a need for new equipment because of the increased workload in the department. The existing machinery was also having frequent breakdowns and the downtime worsened the problem of failing to cope with demand. New equipment is also needed in order to harness new innovations that are not 
included in the present system. In this case, the department has to engage administration to convince them that they need new diagnostic equipment urgently. Stakeholders have to come to a decision to purchase as well as the time frame within which the action should be taken. Case 3: Two hospitals had merged into a bigger unit. There was a need to have a larger capacity to take care of the greater client base of the combined entity. The need to harmonise the systems in the two divisions to enable sharing of resources also required that the two make use of similar equipment. The administration had to be convinced of the benefits of acquiring new equipment. As one of the interviewees pointed out: 'It was born out of a need to standardise all the service across the Trust. Each hospital's laboratory had a different analyser all giving different results. This created problems during interpretation of results by doctors'

\subsection{Specification}

Specification is left to the laboratory personnel who are the main operators of the diagnostic equipment. After they specify the equipment a cluster of apposite suppliers can be identified. This study noted the exclusion of biomedical engineers who are supposed to verify the specifications determined by potential suppliers from the process. This emerges the risk of buying equipment, which does not have the capabilities specified by suppliers. Other stakeholders have only a little part to play as they do not have the proper technical knowledge. A characteristic example was given by an interviewee: 'PCU and GPs were not directly involved in specification processes. These people use our service by purchasing a bulk service from the hospital. Hence, directly they would not have been involved, but their requests would have been channelled at the point they purchase the service. Also internal users from the hospital itself where not represented directly during specification. But their goals are incorporated into hospital goals. Thus, through meeting hospital goals, the laboratory is deemed to have met all its users' demands'.

\subsection{Selection of suppliers}

Selection of suppliers is done by PC and is convened and chaired by the PD. PC is guided by organisational guidelines imposing that procurement is subject to tender process. The adjudication of tenders follows an established scoring process and one of the interviewees summed it up by stating: 'We went through the scoring process, they scored differently. So when we scored them against the specification, we had eight pages of factors. For each factor, a company would score very high or very low in the case of very low performing. We finally tallied the scores for each option, which were different'

This method of selection - although has been designed to ensure fairness and competition among suppliers - does not guarantee the best results. It was observed by one interviewee that: 'Not all aspects were thoroughly considered such as patient safety and manufacturer claims were never thoroughly evaluated. It was taken for granted that proof of Food and Drug Administration (FDA) accreditation confirmed that the product was up to standard.'

\section{Discussion}

The idea of stakeholder salience does not appear to play a large part in the decision-making process during procurement for diagnostic equipment in hospitals. Stakeholder salience as described by Win and Keller (2001) does not seem to be considered directly as shown by the exclusion of key stakeholders like the biomedical engineers from the decision-making process. When the purchase decision is made there is no deliberate effort to identify and engage the key stakeholders. This failure to observe the stakeholder theory which according to Boostra and De Vries (2008) has found 
application in the study of organisational systems can result in unsatisfactory purchased products. This comes in line with Cavanugh (1984), who pointed out the biomedical engineers wield power in terms of ensuring that the right decision is made because of the specialist knowledge which they possess and should be given prominence in the specification of equipment to be bought. In the same light, the CFO also possesses immense power over the decision-making process because ultimately purchase cannot be progressed without their approval of payment (Pfeffer, 1992). This appears to be recognised as they are engaged from the very beginning of the process. PD is also in a position of power as they have not only to approve but carry out the purchase decision.

The procurement process has ignored the ED, which tends to delay the installation of the equipment and hence the benefits from the investment are also delayed. Nguyen et al., (2009) noted that position, resources, and expertise are a key source of stakeholder power. However, hospital procurement committees appear not to take this into account. Another key stakeholder who has been ignored in the process is the PCU. Rowley (1997) postulated that multilateral contracts which exist among stakeholders dictate stakeholder behaviour and as a result determine the final demands a stakeholder can demand against the organisation's goals. Where their preferences are ignored primary healthcare users might turn to other alternatives which offer quicker services, lower costs or whose findings they have more confidence in. Although the attributes of power, legitimacy, urgency and proximity are not actively put into consideration by decision makers in hospitals, they still play a part in shaping the decision-making process.

Mitchell et al., (1997) claimed that powerful constituencies are stakeholders. Our study revealed that the LD, CFO, and PC cannot be dispensed with the procurement process. Without them, it would not be able to make progress towards the final purchase. The fact that they are in a position to affect the outcome of decisions makes them key factors regardless of how one views their role. Frooman (1999) brings up the fact that, whether someone is a stakeholder or not is inappropriate, but the fact that they affect the direction of the organisation and/or project is important. Hospital decisions in procuring equipment are therefore controlled by these parties, no matter if their positions may be viewed as correct or not. According to Phillips (2003), LD would be viewed as normative stakeholders who stand to benefit from the new equipment while PC and CFO are derivative stakeholders who can have an impact on the project's direction or even stop it.

Taking Driscoll \& Starrick's (2004) view that Urgency can either be evaluated from a perspective of the short-term economic results and long-term sustainability the LD has the most of this attribute. Their key function depends on having reliable equipment since in different case they would be unable to perform their primary duties. The administration of the hospital would also have credibility issues if the institution is unable to meet its key responsibilities of providing reliable medical services to their customers. When Proximity is viewed as the depth on which a stakeholder would be involved in a project, LD once again stands out in this respect. Still, the study found that the proximity of the administration is also high as they have the responsibility to achieve performance objectives through the contribution of each department. Furthermore, this study unveiled that hospitals are not versatile when it comes to procedures for purchasing diagnostic equipment. Stringent rules are in place to ensure fairness and competition in selecting suppliers through the tender process. There is a definite preference for managed service contracts inconsistency with the observation by Morse et al. (2008) that outcome measures are gaining in popularity as a basis of the contract.

\section{Conclusion}

Throughout our research, it was ascertained that NHS hospitals do not tend to apply stakeholder analysis as a part of their project planning process. This has in some cases resulted in leaving out key 
stakeholders and thereby bringing about conflict and delays in the process. NHS hospitals are bound by strict guidelines in their procurement processes to avoid bias and ensure competition among potential suppliers and get the best deal. Technical personnel, however, came up with some valid reasons why it would be more suitable to upgrade the present equipment than to undertake radical adjustments or changes. It is, therefore, important that at any stage of the process the weight of the stakeholders should be considered in deciding whether their input is acceptable or not.

\section{References}

Aaltonen, K. and Kujala, J. (2010). "A project lifecycle perspective on stakeholder influence strategies in global projects", Scandinavian Journal of Management, 26:4, pp. 381-397.

Akkermans, H. and Van Oppen, W. (2006). Offensive KPIs: improving buyer-supplier collaboration in interorganisational service supply networks, presented at the International System Dynamics Conference, Nijmegen

Axelsson, B. And Wynstra, F. (2002), Buying business services, Chichester: Wiley.

Boonstra, A. and de Vries, J. (2008) "Managing stakeholders around inter-organisational systems: A diagnostic approach”, Journal of Strategic Information Systems, 17, pp. 190-201.

Boudewijn A. Driedonks, Josette M.P. Gevers, Arjan J. van Weele, (2010). Managing sourcing team effectiveness: The need for a team perspective in purchasing organizations, Journal of Purchasing and Supply Management, 16:2, pp.109-117.

Carroll, A. B.(1993). Business and society. Cincinnati, OH: South-Western.

Cavanaugh, M. S. (1984). A typology of social power. Power, Politics, and Organizations: A Behavioural Science View. Chichester: John Wiley, 3-20.

Cavinato, J.L. (1999) "Fitting purchasing to the five stages of strategic management", European Journal of Purchasing and Supply Management.

Clarkson, M.E. (1995). A Stakeholder Framework for Analyzing and Evaluating Corporate Social Performance. Academy of Management Review, 20:1, pp. 92-117;

Congressional Budget Office (2007). "The Long-Term Outlook for Health Care Spending: Sources of growth in projected federal spending on Medicare and Medicaid". Washington DC: Congress of the United States Congressional Budget Office, available at: www.cbo.gov/sites/default/files/cbofiles/ftpdocs/87xx/doc8758/11-13-lt-health.pdf (accessed 18 December 2015).

Cousins, P. D., Lawson, B., Petersen, K. J. and Handfield, R. B. (2011), Breakthrough Scanning, Supplier Knowledge Exchange, and New Product Development Performance. Journal of Product Innovation Management, 28, pp. 930-942

Dahl, R. A. (1957). The concept of power. Behavioural Science, 2, pp. 201-215. 
Donaldson, T., and Preston, L. E. (1995). The stakeholder theory of the corporation: Concepts, evidence, and implications. Academy of Management, The Academy of Management Review, 20:1, pp. 65-88.

Driscoll, C., \& Starik, M. (2004). The primordial stakeholder: Advancing the conceptual consideration of stakeholder status for the natural environment. Journal of Business Ethics, 49, pp. 55-73.

Eisenhardt K.E. (1989). "Making fast strategic decisions in high-velocity environments". Academy of Management Journal, 32: 543-576.

Etzioni, A. (1964). Modern organizations, Englewood Cliffs, NJ: Prentice-Hall.

Finch, D., Hillenbrand, C., \& Rubin, H. (2015). Proximity, Strategic Groups and Reputation: An Exploratory Study of Reputation in Higher Education. Corporate Reputation Review, 18(3), 174-194.

Fitzsimmons, J. A., Noh, J. and Thies, E. (1998). Purchasing business services, Journal of Business \& Industrial Marketing, vol. 13:4/5, pp.370-380

Freeman, R. E (1984). Strategic management. A stakeholder approach. Boston: Pitman

Freeman, V.T. and Cavinato, J. L. (1990). Fitting purchasing to the strategic firm: Frameworks, processes, and values. Journal of Purchasing and Materials Management 26: (1), pp. 15-20.

Freidman, A.L. and Miles, S. (2002) Developing stakeholder theory', Journal of Management Studies, vol. 39 , no. 1, pp. 1-21.

Frooman, J. (1999) "Stakeholder influence strategies", Academy of Management Review, 24, vol. 24, pp. 191-205.

Gelderman, C. J. and Van Weele, A. J. (2005), Purchasing Portfolio Models: A Critique and Update. Journal of Supply Chain Management, 41, pp. 19-28.

Goodpaster, K.E. (1991). Business Ethics and Stakeholder Analysis. Business Ethics Quarterly, 1, pp 53-73.

Grönross, C. (2000), Service Management and Marketing: A Customer Relationship Management Approach, John Wiley \& Sons, Ltd., (Second edition)

Johnson, M. (2013). Buy-side barriers to e-business technology in the healthcare sector. International Journal of Healthcare Technology and Management, 14(1-2), 110-142.

Kamal, O., Brown, D., Sivabalan, P., and Sundin, H. (2015). Accounting information and shifting stakeholder salience: an industry level approach. Qualitative Research in Accounting \& Management, 12:2, pp.172-200.

Kanter, R. M. (1983). The change masters. New York, NY: Simon \& Schuster.

Martin, S., Yen, D. C., \& Tan, J. K. (2002). E-health: impacts of internet technologies on various healthcare and services sectors. International Journal of Healthcare Technology and Management, 4(12), 71-86. 
Mitchell, R.K., Agle, B.R. and Wood, D.J. (1997) "Toward a theory of stakeholder identification and salience: Defining the principle of who and what really counts", Academy of Management Review, vol. 22, pp. 853-886.

Morse, J.H., Koven, S.G., Mundt, C.J. and Gohman, S.F. (2008) "The Kentucky Initiative in Health Services Contracting: The search for contracting of outcome measures", Journal of Public administration, vol. 31, pp. 639-653.

Neville, B.A., Bell, S.J. and Witwell, G. (2004) "Stakeholder salience revisited: Toward an actionable tool for the management of stakeholders", Academy of Management Proceedings, pp. D1-D6.

Newhouse, J. P. (1992). "Medical care costs: how much welfare loss?". The Journal of Economic Perspectives, 6:(3), 3-21.

Nguyen, N. H., Skitmore, M., and Wong, J. K. W. (2009). Stakeholder impact analysis of infrastructure project management in developing countries: A study of perception of project managers in state-owned engineering firms in Vietnam. Construction Management and Economics, 27:11, pp. 1129-1140.

Parent, M. M., and Deephouse, D. L. (2007). A case study of stakeholder identification and prioritization by managers. Journal of Business Ethics, 75, pp.1-23.

Pfeffer, J. (1992). Managing with power: Politics and influence in organizations. Harvard Business Press.

Phillips, R. (2003). Stakeholder legitimacy. Business Ethics Quarterly, 13:1, pp. 25-41.

Rauner, M. S., \& Heidenberger, K. (2002). Scope and role of strategic technology management in hospitals: the case of Vienna, Austria. International Journal of Healthcare Technology and Management, 4(3-4), 239-258.

Rowley, T. J. (1997). Moving beyond dyadic ties: A network theory of stakeholder influences', Academy of Management Review, vol. 22, pp. 887-910.

Smith, A. D., \& Flanegin, F. R. (2004). E-procurement and automatic identification: enhancing supply chain management in the healthcare industry. International Journal of Electronic Healthcare, 1(2), 176198.

Spekman, R. E., Salmond, D. J., and Lambe, C. J. (1997). Consensus and collaboration: normregulated behaviour in industrial marketing relationships. European Journal of Marketing, 31:11/12, pp. 832-856

van der Valk, W. and Rozemeijer, F. (2009). Buying business services: towards a structured service purchasing process, Journal of Services Marketing, vol. 23:1, pp.3 - 10

Winstanley, D., Sorabji, D., and Dawson, S. (1995). When the pieces don't fit: a stakeholder power matrix to analyse public sector restructuring. Public Money \& Management, 15(2), 19-26. 